\title{
LA FORMACIÓN DE FRENTES DE BRISA ACTIVOS EN LA COMARCA ALICANTINA DEL ALTO VINALOPÓ. EL EPISODIO ATMOSFÉRICO DE 27 DE ABRIL DE 2001
}

\author{
César Azorín Molina \\ Instituto Universitario de Geografía \\ Universidad de Alicante
}

\section{RESUMEN}

Aún cuando las circulaciones estivales de brisa marina pasen desapercibidas para el gran público, percibiéndose éstas simplemente por su efecto dulcificador en las temperaturas de la franja litoral durante los meses centrales del estío, la importancia climática de estos vientos de carácter periódico ha sido centro de preocupación y objeto de estudio desde los orígenes de la ciencia climática. El presente trabajo pretende justificar, a partir del episodio meteorológico de lluvia intensa y granizo de 27 de abril de 2001, la importancia del juego conjunto de vientos locales (brisas de mar-tierra y vientos de vallemontaña) como percutores de primer orden en la génesis de frentes de brisa activos en las tierras del tramo alto del Vinalopó.

Palabras clave: vientos locales, frentes de brisa, lluvia intensa y granizo, comarca del Alto Vinalopó.

\begin{abstract}
The summer sea breeze winds go unnoticed for common people and they are only detected by their sweetening effect on the temperatures on the coast during the middles summer months, the climatical significance of these periodical winds has been the main worry and the theme of study since the beginning of climatical science. This study wants to justify, through the meteorological occurrence of hard rain and hail stone on the $27^{\text {th }}$ of april 2001, the importance that the group of local winds (sea-earth breeze and valleymountains winds) have as main firing pin their genesis of active breeze fronts in the high zones of the «Vinalopó».
\end{abstract}

Key words: local winds, sea breeze fronts, hard rain and hail stone, Alto Vinalopó region. 


\section{El circuito de brisas. Algunos conceptos interesantes}

Al margen de los erróneos planteamientos sobre los mecanismos de los monzones, reflejados en la formulación de nuevos modelos de circulación atmosférica general por el meteorólogo alemán Dove (1837), quién asimiló los monzones asiáticos a un gigantesco sistema de brisas de periodicidad estacional, o a la par las referencias documentadas al supuesto monzón ibérico en la memoria de Manuel Rico de 1851, puesta en tela de juicio con argumentos inapelables por el profesor López Gómez en el marco de la aportación española al congreso de la Unión Geográfica Internacional en la India (1964), será el célebre teorema de Vilhelm Bjerknes (1862-1951) el que constituirá la primera explicación teórica del sistema de brisas de mar y tierra; "si los gradientes de presión y temperatura tienen direcciones distintas, se crea energía que fuerza al aire a circular en el sentido que lleva desde el extremo del vector gradiente de presión al del vector de gradiente de temperatura, por la trayectoria más corta».

La brisa de mar y tierra, entendida como tal, representa un viento de carácter periódico y horario manifestado a partir de factores térmicos, encargados de modificar los campos de presión en situaciones atmosféricas caracterizadas por gradientes báricos en la horizontal apenas contrastados y, por ende, inexistencia de viento fuerte en superficie que las haga irrelevantes al juego y alternancia operado en el período de 24 horas. Muy simplemente y de forma esquemática el mecanismo operaría del siguiente modo: en verano, en un sector costero, el caldeamiento de la superficie de tierra es intenso durante el día, el aire se hace más ligero, se dilata y tiende finalmente a ascender (proceso termodinámico), siendo el

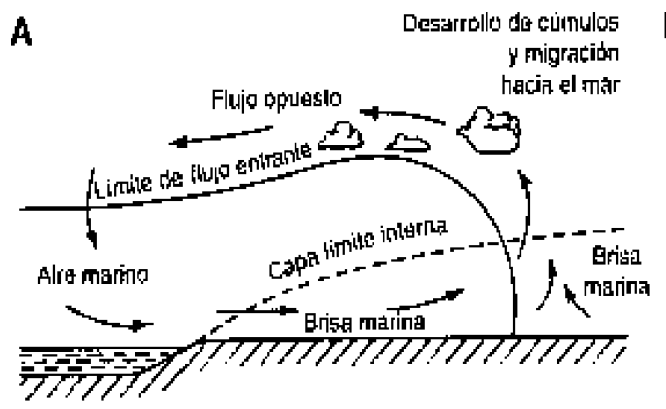

B

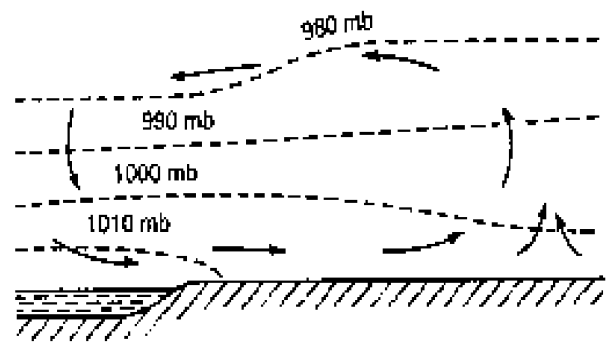

C

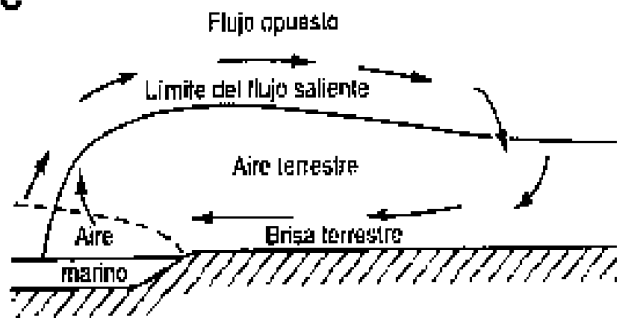

D

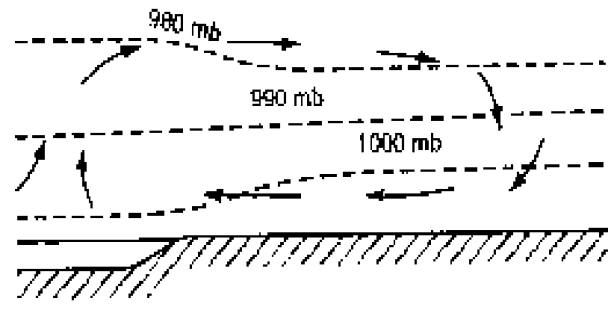

FIGURA 1. Brisas terrestres y marinas diurnas A y B: circulación de brisa marina y distribución de la presión al principio de la tarde con tiempo anticiclónico. C y D: circulación de brisa terrestre y distribución de la presión de noche con tiempo anticiclónico. Fuente: tomado de Barry y Chorley, 1998: 123. 
vacío relativo generado en tierra compensado por la llegada de aire de procedencia marítima, a menor temperatura. A este mecanismo, se le conoce con el nombre de brisa marina, marinada o virazón, y sopla desde media mañana para alcanzar su mayor intensidad tras las horas de más calor (en Valencia, el soplo de este confortable flujo de viento recibe el nombre de «embatà del migdia»). Por la noche, en cambio, las condiciones se invierten, la brisa sopla de tierra a mar, mecanismo denominado terral. Similar proceso se desarrolla sobre las vertientes caldeadas por el Sol, dando lugar a la aparición, en los sectores continentales, de las llamadas brisas de valle o montaña, consistentes en un proceso termodinámico que favorece un ascenso oblicuo del aire durante el día, siguiendo el trazado de la ladera, y una colmatación de éste durante la noche sobre hondonadas, cubetas $\mathrm{y}$ depresiones intramontanas.

Según sintetizan Barry y Chorley (1998: 123-124), en situaciones anticiclónicas, de calma y templanza atmosférica, el caldeamiento durante el día de la columna de aire por encima de la tierra hace que las superficies isobáricas se inclinen hacia abajo en la costa (vid. A y B; brisa marina). Las diferencias de presión, que rondan los $2 \mathrm{mb}$, devienen en el juego de un flujo compensatorio mar-tierra en la capa geográfica, mientras en altitud el dominio corresponde a flujos aéreos de dirección contraria, es decir, acordes con el comportamiento de la circulación general sobre la troposfera libre ${ }^{1}$. Con la llegada del ocaso, los gradientes de temperatura y presión difieren, la temperatura de la columna atmosférica suprayacente a la superficie marina es ahora mayor, lo que fuerza al aire a migrar de tierra a mar, conformando un circuito de vientos contrario al operado durante el día, con flujo opuesto en altitud (vid. C y D; brisa terrestre).

Independientemente de las matizaciones impuestas por la fuerza de Coriolis y de la propia rugosidad del terreno a la hora de justificar la distinta penetración del circuito de brisas hacia el interior, fundamentada la primera de ellas en la incurvación y desvío que experimenta el flujo de viento hacia la derecha en latitudes medias debido a la resistencia impuesta por la citada fuerza, el marco sinóptico juega un papel sobresaliente en la instalación de la circulación de brisas en las regiones levantinas, espacio donde la brisa adquiere rasgos singulares y prototípicos dentro del conjunto del solar peninsular. Las hasta ahora pobres aportaciones de la Escuela española en la publicación de catálogos de tipos de tiempo y situaciones sinópticas, encuentran en las obras de los profesores García Fernández y Martín Vide excepciones a la notable carencia de clasificaciones de escenarios sinópticos de características autónomas. García Fernández incluye, en su obra maestra dentro de la ciencia climática española «El Clima en Castilla y León», un catálogo único, propio y pionero con base en el manejo de la topografía absoluta de $300 \mathrm{hPa}$. En cambio, del profesor Martín Vide destaca su excelente manual «Mapas de tiempo: Fundamentos, interpretación e imágenes de satélite», donde propone 16 situaciones sinópticas para el conjunto de la península Ibérica e islas Baleares. Basándonos en este último catálogo, escenarios sinópticos definidos por situaciones de marasmo y baja térmica pueden considerarse proclives para el establecimiento del circuito de brisas en el levante español. Ambas configuraciones sinópticas ganan protagonismo sobre el escenario peninsular llegado los meses pre-estivales, haciéndolo paralelamente el régimen de brisas. La cuenca del Mediterráneo occidental es receptora durante el estío de configuraciones isobáricas no cerradas, con presencia de isolíneas de presión distanciadas y valores próximos al normal. En cambio, la península Ibérica, por sus matices geográficos, actúa como pequeño continente.

1 Como se detallará más adelante, capital importancia debe ser concedida a la circulación de vientos en altitud, con el fin de justificar el desplazamiento y trayectoria de células convectivas formadas en las tierras del interior alicantino. 
De hecho, durante las horas centrales del período canicular, a favor de índices de nubosidad total exíguos y elevada fracción de insolación efectiva, el intenso caldeamiento del substrato es deudor de la seclusión de una isobara sobre un talweg térmico generalmente débil y consiguiente configuración de una baja térmica, que adquiere singularidad climática en las tierras peninsulares durante el verano ${ }^{2}$.

\section{La importancia climática de los caracteres geográficos en la comarca alicantina del Alto Vinalopó}

Junto a la propia disposición estructural de los relieves prebéticos, la configuración de pasillos y valles intramontanos es aspecto destacado dentro del conjunto de las tierras alicantinas (vid. Figura 2). De hecho, la comarca del Alto Vinalopó, enclavada en el borde noroccidental de la provincia de Alicante comparte, desde un punto de vista fisiográfico y de las unidades del relieve, una marcada dualidad entre alineaciones montañosas y sectores deprimidos, valles y fosas interiores. Encuadrada dentro del dominio morfoestrutural del prebético externo, los principales accidentes montañosos del tramo alto del Vinalopó adquieren clara disposición varisca (SO a NE). A ello, se une la individualización de una línea de fractura dispuesta transversalmente al eje de las béticas, el corredor del Vinalopó, unidad fisiográfica que representa la única apertura favorable hacia el sureste, es decir, hacia la franja litoral alicantina. Acompañando a este pasillo transversal, extendido hacia el noroeste a través de la cubeta interior de Villena y del corredor de Almansa, dos fosas interiores se desarrollan contiguamente y de forma paralela a la directriz y disposición estructural del prebético, los valles de Benejama y Biar, que convergen hacia el noreste con el corredor de Agres.

Por tanto, adquiere especial singularidad climática, a la hora de justificar la génesis de frentes de brisa activos en las tierras del interior alicantino, la compartimentación y configuración geomorfológica. Por ello, a diferencia del dominio ibérico, que aisla a través de sus breves y delgadas líneas de fractura las comarcas interiores de todo influjo mediterráneo, las directrices morfoestructurales béticas son proclives al juego conjunto, aunque con matices varios, de la influencia del ingente reservorio energético mediterráneo, así como de los rasgos climáticos propios de unas tierras en transición, interfase entre la seca región del sureste ibérico y la rigurosidad climática meseteña. La importancia de los relieves más destacados de la comarca, entre los que destacan las unidades estructurales de la Sierra de Salinas, Enmedio, Castellar, Alhácera, Peña Rubia, Morrón, Solana, Fraile y Fontanella, se fundamenta en el hecho de que, éstas alineaciones, como factores intrínsecos de los parámetros atmosféricos, condicionan éstos a través de su altitud, exposición u orientación, declives o sistemas de pendientes y su carácter más o menos anfractuoso y accidentado.

Al margen de las disimetrías pluviométricas marcadas por la disposición de los relieves, con acentuación de áreas de abrigo aerológico, los accidentes montañosos matizan las pautas en la formación y génesis de núcleos convectivos. En este sentido, la orientación y exposición de vertientes se manifiesta en los contrastes térmicos operados entre solana y umbría, así como entre levante y poniente. De hecho, a igualdad de condiciones, los rayos solares inciden más próximos a la vertical en la vertiente de solana que en la de umbría, manifestándose en su caso en la colonización de unos poblamientos vegetales ralos y dispersos, adaptados a unas condiciones de elevada insolación y exígua humedad. Estos

2 La baja térmica, que acompaña durante buena parte del estío las cartografías o análisis en superficie del Boletín Meteorológico publicado por el I.N.M., actúa como un verdadero aspirador del aire cálido y húmedo que circunda en su fachada oriental a la península Ibérica (Mediterráneo). 


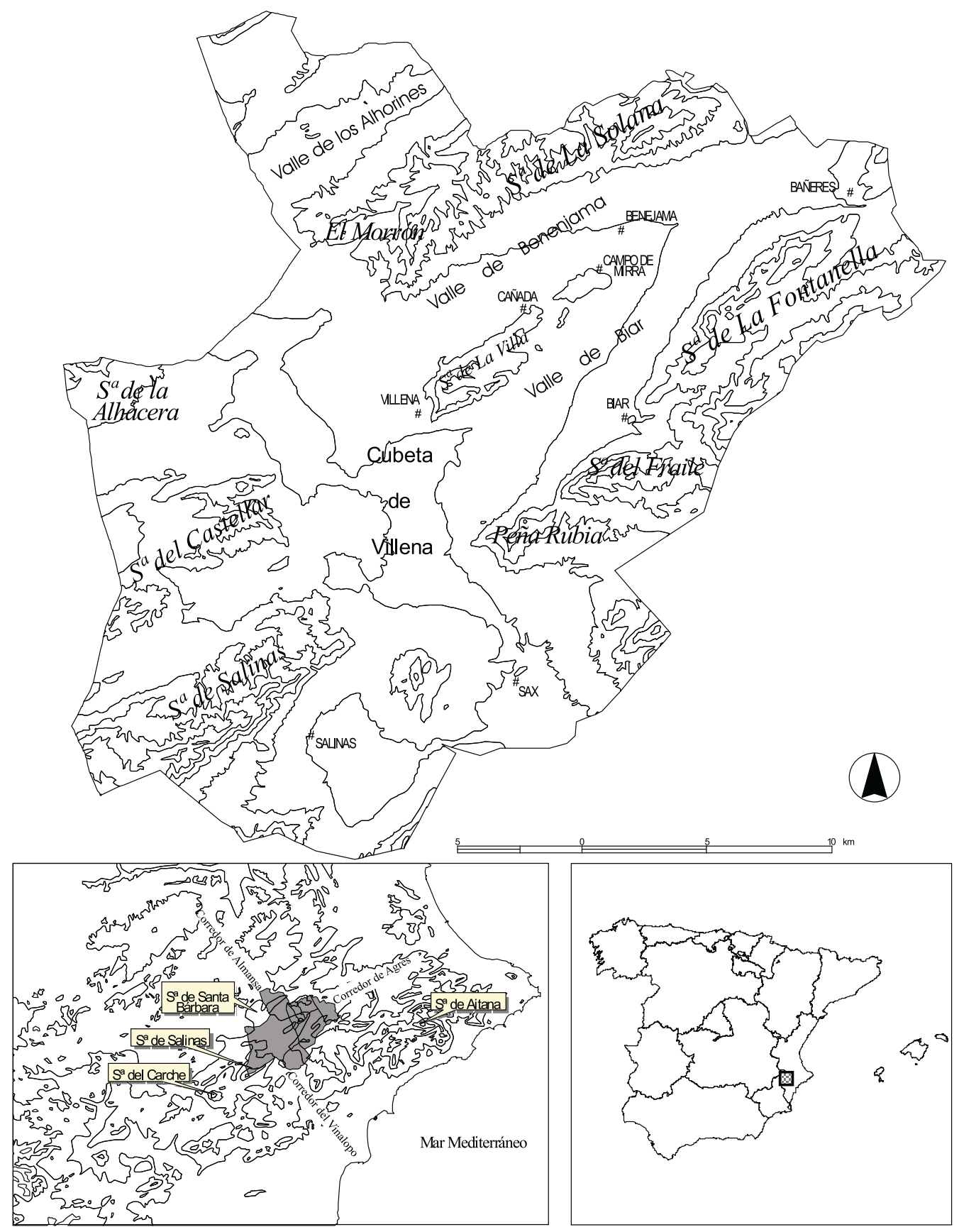

Elaboración propia.

Figura 2. Localización de la zona de estudio. 
paisajes sumamente agrestes, propios de las laderas de solana, desnudas y descubiertas de un tapiz vegetal uniforme, favorecen, durante las horas centrales del día, un intenso caldeamiento del aire suprayacente al substrato calizo, que deriva a su vez en una expansión y dilatación de éste. Así, coincidiendo con las horas cenitales y siempre y cuando no exista viento en superficie que ayude a desvirtuar los ascensos termodinámicos, la brisa de valle sigue el trazado de las laderas de los principales sistemas prebéticos de la comarca, animando así la puesta en juego de uno de los percutores fundamentales en la consolidación de todo frente de brisa, núcleo convectivo o línea de turbonada: las corrientes térmicas circunscritas a un ámbito local (vertientes de solana del prebético externo).

De manera conjunta, efectos orográficos y friccionales, derivados del choque de la marinada procedente del segundo cuadrante con los relieves circundantes a la cubeta de Villena, son responsables, por último, de la convección forzada de un aire sumamente inestable, proyectado contínuamente en la vertical.

A su vez, junto a la importancia que tienen los relieves en la consolidación de brisas de valle de características autónomas, más pueden tenerla la presencia de pasillos tranversales al eje y directriz de las béticas. En este sentido, el corredor del Vinalopó representa un elemento geográfico sumamente determinante a la hora de justificar el crecimiento de activos núcleos tormentosos en las tierras del término villenense, puesto que su penetración perpendicularmente a la orla montañosa del prebético externo permite la canalización de flujos marítimos algunas decenas de kilómetros hacia el interior. A tenor de lo indagado en algunos trabajos de campo, se ha comprobado la penetración tierra adentro, aunque con dificultades, de la brisa marina, flujo marítimo que, aún cuando no adquiere los rasgos termohigrométricos de origen, resultado de una progresiva desnaturalización en su desplazamiento hacia el interior, sí es evidente en el comportamiento de algunos parámetros atmosféricos afines, principalmente manifestado en su efecto perturbador del tiempo atmosférico en puntuales jornadas del semestre estival. La cubeta de Villena, abierta hacia el SE a través de la bocana del eje transversal del Vinalopó, es partícipe del efecto dulcificador de una brisa marina notablemente desvirtuada de sus rasgos prístinos adquiridos en su fuente o región manantial; las tibias aguas del mar Mediterráneo ${ }^{3}$. Asimismo, aunque la red oficial de observación meteorológica sigue evidenciando lagunas importantes, como por ejemplo el dominio de estaciones pluviométricas frente a la escasez de puntos de observación de primer orden, así como la carencia de registro contínuo de velocidad y dirección del viento ${ }^{4}$, parámetro sumamente importante a la hora de estudiar la penetración hacia el interior de la circulación de brisa marina, es de notar que la observación exhaustiva y pormenorizada de un aventajado observador en meteorología puede servir de apoyo con el fin de justificar la llegada de la marinada a las tierras del tramo alto del Vinalopó.

En su caso, la observación directa de la temperie durante los meses caniculares del año, ayuda a confirmar la colmatación de una masa de aire sensiblemente desnaturalizada a la cubeta interior de Villena. Con la simple ayuda del termómetro e higrómetro, y siempre y cuando la configuración de campos de presión sobre el espacio sinóptico peninsular y

3 Al respecto de la distinta penetración del circuito de brisas marinas al interior alicantino, Gil Olcina y Olcina Cantos señalan «En el tramo alto del valle del Vinalopó la brisa accede con dificultades y el grado de continentalización es mayor. Si bien, en días de especial intensidad, la brisa logra sobrepasar el umbral de Sax, y colma entonces la cubeta de Villena, e incluso el valle de Beneixama, aunque se trata de un cuerpo de aire bastante desnaturalizado, y estaríamos en los mismos límites de posible influencia de una marinada secundaria» (vid. Gil, dir., 2000: 32-33).

4 La observación meteorológica de nuestra provincia adolece, además de estaciones meteorológicas de montaña, de observatorios con registro contínuo de precipitación (pluviógrafos), dirección y velocidad del viento (anemocinemógrafos). La reciente instalación de una red de estaciones automáticas por el IVIA (Instituto Valenciano de Investigaciones Agrarias) puede mejorar, a largo plazo, el estudio de ambas variables del clima. 
cuenca del Mediterráneo occidental muestre gradientes báricos en la horizontal muy bajos, la llegada de la marinada a las tierras interiores será todo un hecho.

De este modo, a media mañana, los exíguos valores en la fracción de saturación, del orden de 0’2-0’3, pronto se disparan, la temperatura desciende ligeramente, al tiempo que la transparencia de la masa atmosférica se vuelve contraria. Desde el propio núcleo urbano de Villena, la nitidez de los contornos montañosos del borde occidental del término villenense (alineación prebética Sierra del Carche-Sierra de Salinas, Sierra de Enmedio, Sierra del Castellar, Cabezo de la Virgen y Sierra Alhácera) se difuminan, mientras que a últimas horas del día tocas y monteras de Stratocumulus cubren los puntos culminantes de los principales accidentes serranos que circundan el curso alto del Vinalopó. Si la tónica meteorológica no varía, al día siguiente el proceso de condensación habrá operado sobre las superficies frías, con formación de abundante rocío e, incluso, si la condensación es aún más copiosa, no será nada extraño la observación de bancos de niebla y neblinas repartidas irregularmente sobre hondonadas y sectores deprimidos de la extensa y amplia cubeta lagunar de Villena.

\section{Circulaciones de brisa marina: su importancia en el estallido de frentes de brisa activos en las tierras del tramo alto del Vinalopó}

Si la importancia climática del soplo de este viento horario sobre el espacio litoral alicantino radica en una atenuación de los contrastes térmicos, es decir, mengua de las oscilaciones térmicas diarias y, por ende, de la amplitud térmica, matizando al tiempo los rasgos higrométricos de todas aquellas áreas afectadas por su influencia, la llegada de la marinada a tierras del interior alicantino es, si cabe, aún más determinante.

Tal y como han indagado Olcina Cantos y Miró Pérez (1998: 117), a través de trabajos de campo y manejo de datos analíticos (consulta de las bandas del termohigrógrafo de Castalla y de los datos sobre frecuencia de dirección y velocidad media del viento facilitados por el observatorio meteorológico de «El Altet»), es a partir de los meses de inicio de la temporada estival (pre-estivales; mayo y junio), cuando, a favor de un máximo diferencial de temperatura entre la superficie de tierra y mar, el virazón alcanza una mayor entidad y grado de penetración tierra adentro. Empero, la circulación de brisa marina sigue siendo protagonista en las jornadas de tiempo bonancible del período canicular, aunque el grado de canalización hacia el interior, resultado de una atenuación del citado contraste térmico, se ve ahora notablemente dificultado y obstaculizado, aunque no por ello queda exenta de poder colmatar, en jornadas de especial intensidad, la cubeta y fosa interior de Villena.

Por todo ello, la singularidad climática de la circulación de flujos de viento de carácter superficial, circunscrita a espesores que no suelen ser superiores a los 5.000 metros, no queda reflejada exclusivamente en su carácter saludable en las tierras ribereñas al Mediterráneo, sino que, por doquier, la brisa marina representa un percutor de primer orden en la génesis y consolidación de activos núcleos convectivos o frentes de brisa activos en las comarcas del interior de la provincia lucentina. Es necesario, por tanto, establecer algunas matizaciones sobre la existencia de dos tipos de frentes de brisa, estables e inestables, así como las improntas que confieren cada uno de ellos al tiempo atmosférico vivido en las tierras de la comarca del Alto Vinalopó.

\subsection{Frentes de brisa estables}

- Se desarrollan en los meses centrales del verano (julio-agosto).

- Escena sinóptica. a) En superficie el dominio corresponde a las altas presiones subtropicales (Anticiclón de Azores) que ganan latitud y sitúan su ápice al oeste de 
la península, entorno al paralelo $40-45^{\circ}$ N. Sobre la península Ibérica, suele ser frecuente la sucesión de jornadas con predominio de la baja térmica, aislada en el interior del solar ibérico o inserta dentro de un talweg térmico extendido desde el norte de África, con eje dispuesto de norte a sur (pronto invertida en altitud; 850$700 \mathrm{hPa}$ ). Sobre la cuenca mediterránea, la presión ronda valores próximos al normal, con protagonismo de situaciones de marasmo o pantano barométrico. b) En cambio, en altitud (topografías absolutas de 500 y $300 \mathrm{hPa}$ ), el predominio corresponde a la presencia de crestas y dorsales de aire tropical (Tc y Tm), que garantizan la estabilidad de toda la columna troposférica.

- La subsidencia impuesta por las altas presiones subtropicales, desvirtuadas en superficie por la presencia de bajas presiones relativas o situaciones de marasmo, crea un nivel de inversión que acota los ascensos de origen térmico e impide la lluvia.

- Derivado de ello, la nubosidad desarrollada suele ser escasa y decorativa, con fracción de insolación apenas interferida. Ésta se restringe a la aparición de algunas pinceladas de nubes de buen tiempo, Cumulus fractus y Cumulus humilis que durante las horas centrales del día dejan verse sobre la bóveda celeste a la vista del observador, para disiparse con la llegada del ocaso (Stratocumulus vesperalis). Si la entidad y grado de penetración de la brisa es importante durante el verano, pero las condiciones de calmaria dominan la dinámica atmosférica, puede suceder que, sobre las principales alineaciones montañosas del borde meridional del término de Villena, directriz marcada entre la Sierra de Salinas-Peñarrubia-Fraile-Fontanella, se desarrolle nubosidad de tipo orográfico, nubes que quedan adosadas en forma de toca a los puntos culminantes de estos accidentes montañosos; Stratocumulus.

- Temperaturas máximas sensiblemente atemperadas $\left(30-35^{\circ} \mathrm{C}\right)$ con relación a poblaciones afines climáticamente. Así, el mercurio termométrico suele diferir, en contra de lo normal, de las máximas registradas en observatorios donde cobra mayor protagonismo la continentalidad; Almansa y Albacete (las temperaturas máximas suelen enfilarse, durante los meses centrales del estío, a valores próximos a la marca de los $40^{\circ} \mathrm{C}$ ).

- Inflexión en la fracción de saturación, con ascenso en los porcentajes de humedad relativa del aire.

- Formación de hidrometeoros característicos: nieblas, neblinas y rocío.

\subsection{Frentes de brisa inestables}

- Atendiendo a la conceptualización del clima mediterráneo por parte del climatólogo francés Durand-Dastés, como un clima de alternancia, con dominio de la Circulación General del Oeste en invierno, con influencia del Anticiclón de Azores en verano y con paroxismos de instalación en las estaciones equinocciales, es en este período de paroxismos, es decir, de inestabilidad y perturbación del tiempo atmosférico (atmósferas baroclinas), cuando gana protagonismo el desarrollo de frentes de brisa inestables sobre el tramo alto del Vinalopó. Asimismo, pueden individualizarse dos épocas especialmente proclives: a) Meses pre-estivales de mayo y junio (a favor de una mayor entidad de la marinada) y b) Un segundo período, secundario éste, que coincide con la transición entre la época del verano astronómico y la entrada del otoño (segunda quincena de agosto y primera del mes de septiembre) ${ }^{5}$.

5 Olcina Cantos ha comprobado la relación entre la época del año de desarrollo de frentes de brisa activos y la frecuencia mensual de episodios meteorológicos de granizo en tierras alicantinas, concentrada entre los meses de mayo-junio y agosto-septiembre. 
- El marco sinóptico generador de frentes de brisa activos tiene como primer percutor la irrupción de aire anormalmente frío sobre la troposfera media y superior. A diferencia de las inversiones térmicas, que devienen en frentes de brisa estables, ocioso es encarecer que si los mecanismos de superficie y altitud operan sincrónicamente la inestabilidad resulta intensificada. Así, se ha comprobado que cada ciclo de brisas transcurre entre el paso de dos perturbaciones, de tal modo que tras la pasada de una perturbación y la llegada de una masa de aire de características térmicas más rigurosas el circuito de brisas gana en duración, intensidad y penetración hacia el interior (Pérez, coord., 1994: 67). Con ello, el juego conjunto de aire cálido y con elevada carga higrométrica conducido y vehiculado por la circulación de virazón siguiendo el eje del Vinalopó, junto a la irrupción de aire frío sobre la troposfera media y superior, derivan en gradientes supraadiabáticos $\left(+1^{\circ} \mathrm{C} / 100 \mathrm{~m}\right)$ que intensifican la inestabilidad absoluta en las tierras del interior alicantino. Normalmente, el escenario sinóptico de todo frente de brisa activo responde a las siguientes premisas: a) Anticiclón retirado al Atlántico, b) Presencia de un débil gradiente bárico sobre la mitad oriental y cuenca del Mediterráneo occidental, c) Transgresión de isotermas en forma de valle planetario (generalmente, ondas cortas atmosféricas de aire Pm, de gran longitud y escasa amplitud de onda) en las topografías absolutas. El aire frío de altitud puede tener reflejo horas más tarde en los análisis en superficie a través de la formación de bajas presiones de origen dinámico.

- La nubosidad asociada a frentes de brisa activos responde a la sucesión de los siguientes estadíos nubosos: a) La colmatación de la brisa marina a la cubeta de Villena a media mañana se deja notar con la aparición de nubosidad parcial de tipo bajo, Stratocumulus stratiformis (nubes extendidas en capa o en manto horizontal de gran extensión), Stratocumulus castellatus (de aspecto almenado en su región superior, con marcadas protuberancias cumuliformes en forma de torrecillas), $\mathrm{Cu}$ mulus fractus y Cumulus humilis, b) Coincidiendo con las horas centrales del día, la inestabilidad absoluta presente sobre la columna troposférica favorece el crecimiento de nuevas formaciones nubígenas de cúpulas protuberosas que denotan la pujanza de los movimientos ascendentes (Cumulus mediocris, Cumulus congestus y Cumulonimbus. vid Foto 1), muchas de ellas formadas a partir de nubes estratificadas en bajos niveles, del género Sc (Cumulus y Cumulonimbus stratocumulogenitus), con nivel de base apenas a sólo 1.000 ó 1.200 m (ancladas sobre la Sierra de Salinas, Sierra de Santa Bárbara, etc.) y c) Restringida la marinada con la llegada del atardecer, la nubosidad de desarrollo vertical deja de crecer, dando como resultado la génesis de formaciones nubosas de amplia base, extendida en la horizontal y con cimas achatadas (Stratocumulus cumulogenitus).

- Temperaturas máximas estables o, por lo general, sensiblemente más bajas en comparación con el valor máximo absoluto registrado en jornadas precedentes (justificado por la presencia de aire frío sobre la columna atmosférica y el efecto parasol inducido por las formaciones nubosas desarrolladas).

- Inflexión en la curva de humedad relativa del aire. Por lo general, el mayor grado de continentalidad de la cubeta de Villena respecto a otras fosas del interior alicantino, retarda la colmatación de la marinada, que accede a la cubeta horas después del mediodía.

- Estallido de núcleos convectivos y tormentas vespertinas de carácter virulento, capaces de desaguar, en el intervalo de apenas unos minutos, volúmenes de agua verdaderamente desorbitados, superiores a los $150 \mathrm{~mm} / 24 \mathrm{~h}$. Estos aguaceros sue- 
len ir acompañados de abundantes descargas de electricidad atmosférica y son responsables de la precipitación de núcleos sólidos, de consecuencias aciagas para el agro de la comarca alicantina del Alto Vinalopó.

\subsection{Posición y trayectoria de desplazamiento de frentes de brisa activos, núcleos convec- tivos y líneas de turbonada en las tierras del tramo alto del Vinalopó}

La configuración geomorfológica de las tierras del Alto Vinalopó determina, por su singularidad y dicotomía estructural existente entre relieves, fosas y cubetas, distinto grado de penetración de la marinada, lo que viene a justificar la posición final del frente de brisa activo, que generalmente coincide con los puntos culminantes de la orla montañosa prebética. Sobre esta idea, reiteradamente apuntada por el profesor Olcina Cantos en sus trabajos sobre episodios meteorológicos catastróficos para la actividad agraria en tierras alicantinas, se apoyan las siguientes hipótesis de trabajo:

1) En días con circulación superficial de vientos sensiblemente debilitada, la brisa accede con muchas dificultades a la cubeta interior de Villena y no consigue rellenarla por completo hasta su borde más interior (sierra de Santa Bárbara-sierra del Morrón-sierra de la Solana). Por ello, los efectos friccionales más intensos se producen sobre la alineación prebética sierra de Salinas, Peñarrubia y sierra del Fraile, conformándose un frente de brisa activo anclado a los reseñados relieves montanos. Los chubascos y aguaceros más copiosos se precipitan sobre el borde meridional del término villenense, excluido el propio núcleo urbano de Villena, alcanzando máxima intensidad en un área de terreno que une las tierras colindantes al municipio vecino de Sax y la Colonia de Santa Eulalia (pedanía perteneciente a Villena), tal y como sucedió en el episodio atmosférico de 26 de mayo de 1998 («la Vereda» 1'7 mm y la finca «los Frutales» > $170 \mathrm{~mm}$ ).

2) Cuando el grado de penetración de la circulación superficial de vientos es, si quiera, mucho más intenso, la marinada consigue sobrepasar el umbral de Sax, colmatando posteriormente la cubeta interior de Villena. En este caso, el relleno se realiza por completo y la brisa consigue acceder hasta el mismo borde interior de la fosa. Ahora, el choque y fricción de estos vientos superficiales (efecto disparo en la vertical) tiene lugar sobre el cíngulo montañoso septentrional de la cubeta, integrado por las sierras de la Alhácera, Santa Bárbara, Morrón y sierra de la Solana, quedando focalizado el frente de brisa sobre la reseñada barrera orográfica del prebético externo ${ }^{6}$. Destaca, per se, el singular episodio meteorológico de 18 de junio de 1997. Registros del orden de $200 \mathrm{~mm}$ de precipitación fueron medidos por el pluviómetro del observatorio meteorológico oficial de la finca «la Vereda», valor que demuestra la entidad pluviométrica de los frentes de brisa inestables. No obstante, los totales pluviométricos pueden ser comparados, siempre y cuando estemos hablando de eventos meteorológicos de rango extraordinario, con los chubascos y aguaceros que azotan durante época tardo-estival la fachada del levante peninsular. Atendiendo a esta segunda posición, puede suceder que mientras observatorios del sureste de Castilla-La Mancha quedan al margen de la inestabilidad atmosférica absoluta propiciada por la entrada de la

6 Según viene recogido por José María Soler (1993), estas formaciones nubosas desarrolladas sobre el extremo septentrional de la comarca del Alto Vinalopó reciben el nombre de «Torres de Valencia» (nubes del género Cumulonimbus) en las poblaciones de Benejama, La Cañada y Villena. 
brisa marina (Almansa), los chubascos en forma de lluvia y granizo precipitan con especial virulencia sobre toda la cubeta de Villena ${ }^{7}$.

Junto a la distinta posición del frente de brisa, que difiere según el mayor o menor grado de penetración de vientos superficiales procedentes del segundo cuadrante hacia el interior, se ha comprobado, a través de trabajos de campo realizados por investigadores adscritos al Laboratorio de Climatología de la Universidad de Alicante; Olcina Cantos, Rico Amorós y Miró Pérez, que existe una correspondencia e interacción mútua entre la trayectoria adquirida por el núcleo convectivo, que sigue la dirección marcada por los flujos de viento implantados sobre la troposfera media y superior, y la compartimentación estructural de las distintas unidades fisiográficas: disposición de relieves, valles y cubetas. En este sentido, extrapolando las conclusiones a las que han llegado algunos de los citados investigadores al caso de la comarca alicantina del Alto Vinalopó, resulta ocioso encarecer el hecho de que pueden individualizarse verdaderos corredores o pasillos de circulación frecuente de frentes de brisa activos, flanqueados por relieves destacados. Cuatro serían, para el caso de las tierras del tramo alto del Vinalopó, los corredores orográficos con directrices acordes a las corrientes en chorro de altitud ${ }^{8}$.

a) La cubeta de Villena, dispuesta transversalmente a la disposición de las béticas. Cuando los vientos con velocidades de chorro adquieren componente de NO a SE, la célula convectiva adquiere un desplazamiento hacia el sureste a través del eje del Vinalopó. El enfrentamiento de flujos de dirección contraria entre altitud y superficie, es responsable de la aparición de una línea de choque, sobre la cual la marinada se encarga de retroalimentar de materia prima al frente de brisa (ingente aporte de calor y humedad), traducida en la precipitación de fuertes chubascos vespertinos (vid. episodio atmosférico de 27 de abril de 2001).

b) El Valle de Benejama, desarrollado entre la alineación sierra del Morrón-sierra de la Solana y la sierra de la Villa. Su disposición, acorde con la directriz de las béticas, canaliza las células convectivas hacia levante a partir de flujos de viento en altitud que adquieren direcciones del oeste y suroeste (vid. episodio atmosférico de 31 de agosto de 2001).

c) El Valle de Biar, flanqueado por las sierras de la Villa y Peña Rubia-FraileFontanella. Su disposición es igualmente favorable a corrientes en chorro de componente oeste y suroeste.

d) En el borde septentrional del término villenense, se podría individualizar un cuarto corredor orográfico; el Valle de los Alhorines (la Zafra), desarrollado entre las alineaciones de la sierra de Santa Bárbara y sierra del Morrón. Disposición acorde a los flujos aéreos del tercer cuadrante.

7 A la hora de elaborar una cartografía de riesgo en la actividad agraria, resulta necesaria la distinción entre áreas proclives para la formación y consolidación de células convectivas, y aquellas otras afectadas por la precipitación de núcleos sólidos. En este sentido, las primeras se localizan sobre los accidentes estructurales más elevados, es decir, en relieves de significación de ascensos (por convección térmica y forzada), mientras que las segundas se corresponden con sectores de valle, allí donde las corrientes de ascenso en el seno de la nube de tormenta han perdido efectividad y dejan precipitar el granizo (sector periférico de un núcleo convectivo). En virtud de esta idea, es de notar que áreas de recepción de granizadas y sectores de potencialidad agrícola vienen a coincidir, lo que justifica las cuantiosas pérdidas económicas a las que somete, cada año, el pedrisco al agro alicantino.

8 Algunos meteorológos de destacado prestigio nacional, entre los que destacaría, por su amplio currículum en la predicción meteorológica, Eugenio Martín Rubio, aluden a la importancia que debe ser concedida a las corrientes en chorro en altitud. Éstas, además de constituir verdaderos sistemas directivos de la Circulación Atmosférica General, matizan el comportamiento de la atmósfera a distintos niveles. 


\section{La comarca del Alto Vinalopó: enclave geográfico para el desarrollo de frentes de brisa activos. El episodio atmosférico de lluvia intensa y precipitación de núcleos sólidos de 27 de abril de 2001}

\subsection{Introducción}

Las múltiples incógnitas e incertidumbres que subyacen del clima en la actualidad encuentran en estos singulares eventos atmosféricos, los frentes de brisa activos, un ejemplo cotidiano de la importancia que tiene el conocimiento del clima local, plasmación, a menor escala, del comportamiento y devenir de la atmósfera en nuestro planeta. A tenor de ello, a continuación se ilustran algunas de las ideas reseñadas, a partir del episodio meteorológico de lluvia intensa y precipitación de núcleos sólidos de 27 de abril de 2001.

\subsection{Pautas del tiempo atmosférico vivido a partir de la segunda quincena del mes de abril de 2001}

Tras el dilatado período de déficit notable de precipitación vivido en buena parte de las regiones levantinas durante todo el mes de marzo de 2001 y primera quincena de abril, motivado por una primacía de vientos del tercer cuadrante en el escenario sinóptico peninsular, a partir de la segunda década de este último mes el tiempo atmosférico fue especialmente generoso para el agro alicantino, muy necesitado de la lluvia.

A favor del desplazamiento de un vórtice ciclónico sobre la vertical de las tierras surestinas, acompañado por la entrada de flujos de componente marítima en superficie, la temperie lluviosa y destemplada caracterizó la situación atmosférica durante el día 18 de abril, tras una larga tregua meteorológica de tiempo estable y soleado ${ }^{9}$. Las precipitaciones en esta jornada, a excepción de las poblaciones del extremo norte e interior de la provincia de Castellón, fueron prácticamente generalizadas en buena parte de la geografía valenciana, con máximos de precipitación que allí donde la lluvia fue más copiosa se rondaron los $100 \mathrm{~mm}$ medidos en tan sólo 24 horas ${ }^{10}$. Aunque los totales pluviométricos registrados en los observatorios del término villenense no fueron tan sobresalientes (Villena 35'8 mm y «la Vereda» $32 \mathrm{~mm}$ ), la lluvia fue muy bien recibida por los cultivos de secano de toda la comarca del Alto Vinalopó (almendro, vid, olivo y cereal).

Como último precedente a los intensos y tormentosos aguaceros registrados a lo largo del día 27 de abril de 2001, apenas transcurridas dos jornadas del episodio atmosférico de 18 de abril, la lluvia hizo de nuevo acto de presencia en muchos observatorios de la provincia alicantina. Las precipitaciones, aunque no tan copiosas como en el anterior episodio, si dejaron algunos máximos pluviométricos destacados, empero, en ninguna estación se consiguió superar la marca de los $20 \mathrm{~mm}$ de lluvia. En Villena, las precipitaciones registradas oscilaron entre los 5' $5 \mathrm{~mm}$ registrados en el propio núcleo urbano y los 7’2 $\mathrm{mm}$ medidos en el observatorio meteorológico oficial de la finca «la Vereda».

9 El repaso y análisis de las fichas de anotación diaria de precipitación del observatorio meteorológico del núcleo urbano de Villena, revelan la circunstancia de que desde el día 7 de marzo de 2001, jornada en la que llegan a totalizarse $4^{\prime} 8 \mathrm{~mm}$, no hay anotación de precipitación alguna, lo que viene a confirmar el dilatado período de indigencia hídrica vivido en tierras surestinas durante cerca de un mes y medio.

10 Puntualmente, en algunas poblaciones alicantinas los problemas se agravaron por causa de la lluvia, hasta el punto que alguna infraestructura viaria fue deshabilitada por un tiempo. La autovía que une las poblaciones de San Vicente del Raspeig y Castalla fue cortada momentáneamente por los problemas causados por los fuertes chubascos precipitados en la mañana del día 18 de abril de 2001. 
Interesa deternerse, sobremanera, por su relevancia en la génesis y estallido de todo núcleo convectivo, en el comportamiento y curva de los valores térmicos máximos registrados en tierras alicantinas en las jornadas precedentes al desarrollo del frente de brisa activo de 27 de abril de 2001. En este sentido, además de la entrada de la marinada, la acumulación de calor sensible en superficie, a partir de la radiación solar recibida, tiene su importancia en la explicación de la intensidad y virulencia del frente de brisa engendrado. Con la implantación de un haz de isobaras sobre el espacio sinóptico peninsular y el consecuente establecimiento de flujos de procedencia occidental sobre buena parte de las regiones peninsulares (advección del oeste), el mercurio termométrico experimentó un sensible disparo a partir del día 22 de abril, con registros térmicos máximos superiores a la veintena de grados centígrados. A la espera de la llegada y paso de un sistema frontal desde las tierras del poniente peninsular, los valores térmicos diurnos alcanzaron ápice entre los días 23 y 24 de abril, temperaturas máximas que en muchos observatorios meteorológicos de las comarcas centrales de la provincia de Valencia llegaron a superar la marca de los $30^{\circ} \mathrm{C}$ (Játiva). Sobre las tierras del término villenense, el ambiente tibio y caluroso del día 24 de abril se tradujo en una máxima de $28^{\prime} 1^{\circ} \mathrm{C}$ para la estación meteorológica de la ciudad de Villena, valor máximo absoluto para el mes de abril de 2001, acompañado a la par por la mínima más elevada del mes durante la noche del día 25 , de $14^{\prime} 3^{\circ} \mathrm{C}$. Con el paso del frente frío sobre las regiones levantinas y la invasión de aire frío sobre la escena sinóptica peninsular durante los días 25 y 26 (instalación de una vaguada de gran longitud y escasa amplitud de onda, de aire Pm, sobre la troposfera media y superior), las temperaturas se vieron sensiblemente atemperadas, aún cuando los registros termométricos máximos siguieron evidenciando el ingente reservorio de calor sensible acumulado en superficie.

Se detallan, a continuación, los registros máximos y mínimos de temperatura y humedad relativa del aire medidos por el observatorio meteorológico del núcleo urbano de Villena durante las jornadas previas, así como el flujo viento dominante durante esos días.

\begin{tabular}{|c|c|c|c|c|c|}
\hline DÍA & $\mathbf{2 2}$ & $\mathbf{2 3}$ & $\mathbf{2 4}$ & $\mathbf{2 5}$ & $\mathbf{2 6}$ \\
\hline & MÁX./MÍN. & MÁX./MÍN. & MÁX./MÍN. & MÁX./MíN. & MÁX./MÍ́N. \\
\hline T $^{\text {a }}\left({ }^{\mathbf{0}} \mathbf{C}\right)$ & $22^{\prime} 8 / 2^{\prime} 9$ & $26^{\prime} 2 / 12^{\prime} 8$ & $28^{\prime} 1 / 12^{\prime} 3$ & $24^{\prime} 3 / 14^{\prime} 3$ & $23^{\prime} 9 / 7^{\prime} 5$ \\
\hline H $^{\text {a }}(\boldsymbol{\%})$ & $72 / 21$ & $71 / 21$ & $76 / 24$ & $67 / 18$ & $85 / 26$ \\
\hline Viento & O (Poniente) & O (Poniente) & OSO & O (Poniente) & VAR. (Variable) \\
\hline
\end{tabular}

Fuente: Observatorio meteorológico propio. Villena (ciudad).

\subsection{Frente de brisa inestable de 27 de abril de 2001}

La inestabilidad atmosférica, presente desde la segunda quincena de mes sobre las regiones levantinas, concedió un breve paréntesis de tiempo, entre los días 21 y 26 de abril, a unas condiciones atmosféricas de calmaria. El tiempo atmosférico inestable que caracterizó la segunda mitad del generoso mes de abril de 2001 tuvo como mejor reflejo el episodio de aguaceros tormentosos, copiosos e intensos del día 27 de abril.

Al objeto de ejemplificar este evento atmosférico, el frente de brisa inestable, se han recopilado una serie de imágenes que ilustran los sucesivos estadíos por los que transcurrió este interesante y singular fenómeno meteorológico, no por ello impropio en las comarcas interiores de la provincia lucentina (Cubeta de Villena y Hoya de Castalla). De esta manera, se acompaña, además de un análisis sistemático de la temperie vivida el día 27 de 
abril de 2001 sobre las tierras del tramo alto del Vinalopó, de unas ilustraciones que justifican algunas de las hipótesis de trabajo planteadas por los responsables del Laboratorio de Climatología de la Universidad de Alicante, conclusiones que hago extensivas a tenor de lo indagado en las observaciones de meteorología realizadas en la cubeta interior de Villena.

La temperie primaveral fue la protagonista desde primeras horas del día 27 de abril de 2001. De forma continuada se sucedieron momentos con chubascos de intensidad moderada, cielo parcialmente despejado, flujos de viento racheados de dirección variable y valores térmicos máximos suaves (Villena $25^{\prime} 1^{\circ} \mathrm{C}$ y «la Vereda» $24^{\circ} \mathrm{C}$ ), sensiblemente más bajos si se yuxtaponen al contexto y curva de temperatura de días previos. Pese a que la mayor inestabilidad atmosférica se concentró a partir de la segunda mitad del día, con formación de fuertes y asimismo violentas tormentas vespertinas, durante la noche, una extensa banda nubosa procedente de las tierras septentrionales del continente africano favoreció el desarrollo de algunas células convectivas, aunque la actividad pluviométrica de ellas quedó restringida a la precipitación de unos mílimetros de lluvia, aunque de intensidad moderada. A las 4'30 horas de la noche se registraron, en apenas diez a quince minutos, 4'6 mm sobre la ciudad de Villena («lluvia de barro»), mientras el pluviómetro instalado en la finca «la Vereda» apenas llegó a medir unas décimas de precipitación (0’5 $\mathrm{mm})$. Otras cantidades destacadas en la geografía alicantina fueron los $5 \mathrm{~mm}$ medidos en las estaciones meteorológicas de Cocentaina y Alcoy, $1 \mathrm{~mm}$ en Castalla y Elda y 0'2 mm en la propia ciudad de Alicante. Estas primeras lluvias registradas no fueron sino reflejo de los marcados síntomas de inestabilidad absoluta presentes sobre la vertical de las tierras levantinas, responsables de los copiosos aguaceros en la tarde del día 27 de abril.

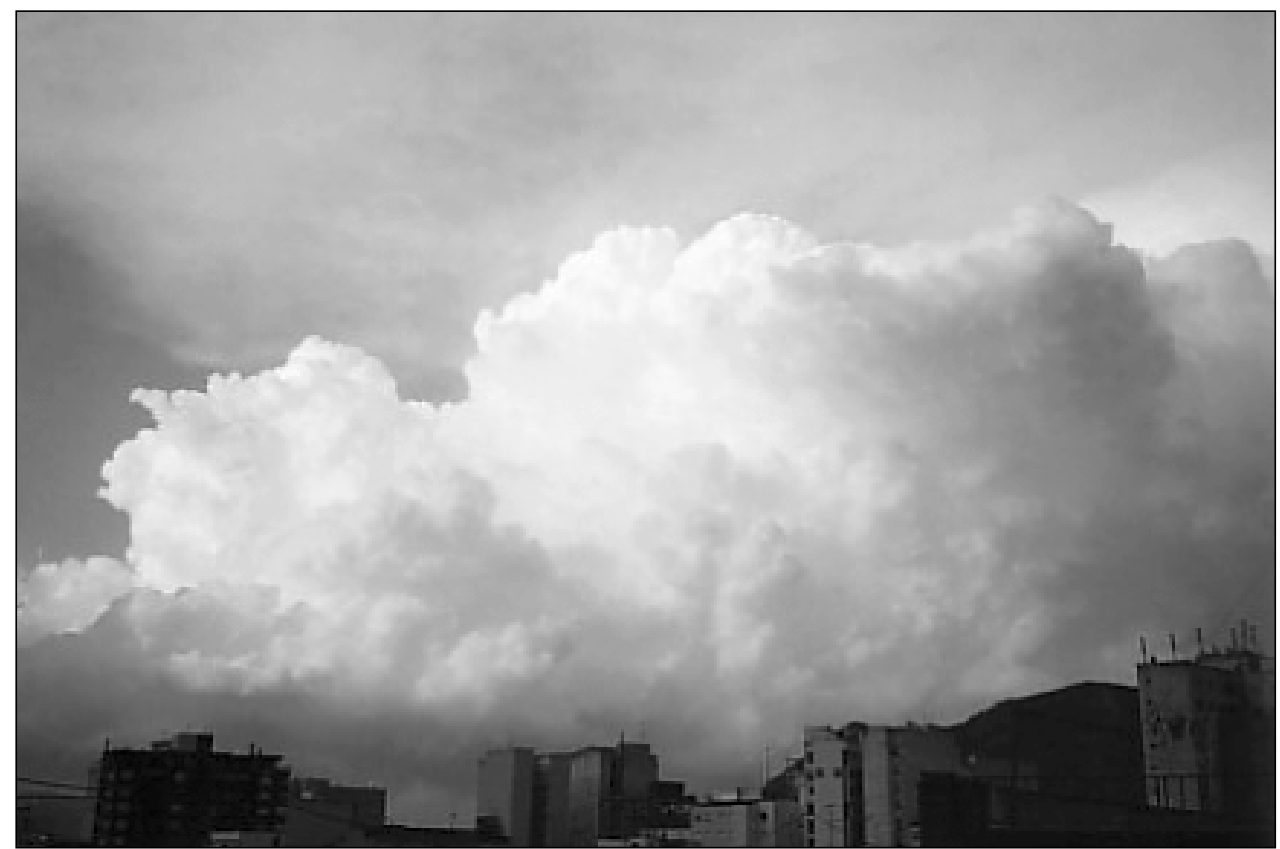

Fото 1. Detalle de los primeros focos convectivos anclados sobre el borde interior del valle de Villena. La formación cumuliforme de la imagen (Cumulonimbus en transición a $\mathrm{Cb}$ cap), alzada impetuosamente sobre el propio núcleo urbano de Villena, sienta su base sobre la alineación montana de la sierra del Morrón-sierra de la Solana, al NNE de Villena. 27 de abril de 2001, 18’40 h. 
De gran espectacularidad es la primera imagen presentada (vid. Foto 1), que ofrece la formación de las primeras nubes convectivas sobre las tierras circundantes al término villenense. En esta jornada, la circulación de brisa marina consiguió sobrepasar el umbral de Sax, colmatando hacia su borde más interior la cubeta de Villena, conformando así un frente de brisa activo focalizado sobre las alineaciones montañosas del margen septentrional de la comarca alicantina del Alto Vinalopó; sierra Alhácera-Santa Bárbara-Morrón-Solana.

Resultado del crecimiento y consolidación de las nubes de marcado desarrollo vertical es la segunda imagen que se incluye (vid. Foto 2), tomada momentos antes de la precipitación del aguacero copioso e intenso. La ilustración, enfocada hacia el horizonte de poniente, muestra el desarrollo del frente de brisa inestable sobre el borde más interior de la cubeta de Villena, conformándose una muralla de gigantescas y enérgicas nubes de desarrollo vertical. Corrientes procedentes del cuarto cuadrante (NO) en altitud justificaron el desplazamiento de los núcleos convectivos siguiendo un rumbo hacia el sureste, acoplándose al eje transversal del Vinalopó, es decir, hacia la comarca del Medio Vinalopó (vid. Mapa 2. Topografía absoluta de $500 \mathrm{hPa}$ ). De este modo, el desplazamiento de la célula convectiva, de noroeste a sureste, contrastaba con el viento cálido y húmedo de superficie, vehiculado por la circulación de brisa marina. El escenario sinóptico de superficie en esta jornada, caracterizado por la existencia de un escaso gradiente de presión en la horizontal (situación de marasmo o pantano barométrico. Vid. Mapa 1. Análisis en superficie), propició la génesis de un circuito de brisas intenso, con circulación de vientos del segundo cuadrante, sirocos y levantes que fueron responsables del aporte de un cuerpo de aire

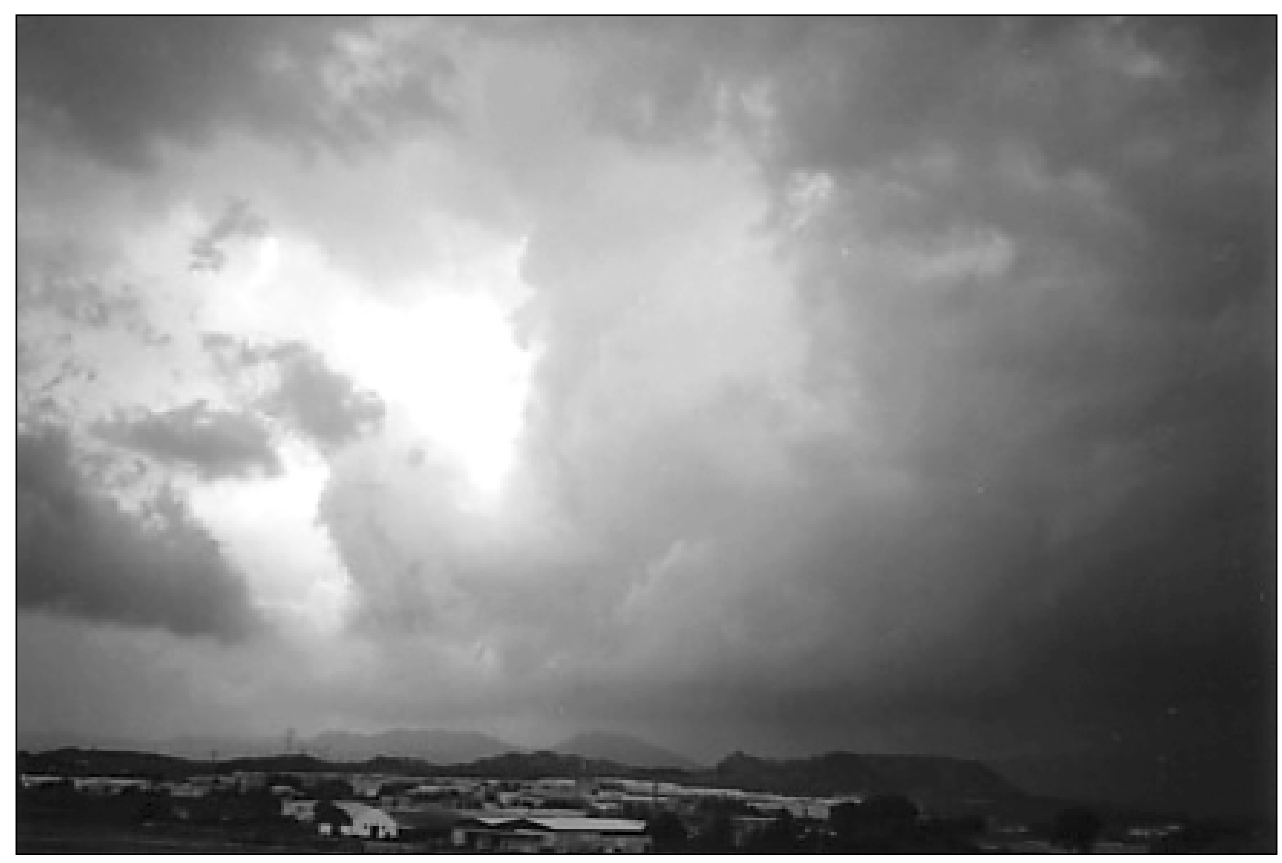

Fото 2. Frente de brisa activo focalizado en el borde interior de la cubeta de Villena. Sobre las tonalidades más oscuras de la parte basal del cumulonimbo, es posible distinguir todo un rosario de jirones desgarrados, conocidos técnicamente con el nombre de pannus. La observación directa de su desplazamiento denotaba circulaciones de viento contrarias entre la capa geográfica y los niveles medios y altos de la troposfera. 27 de abril de 2001, 19'25 horas. 


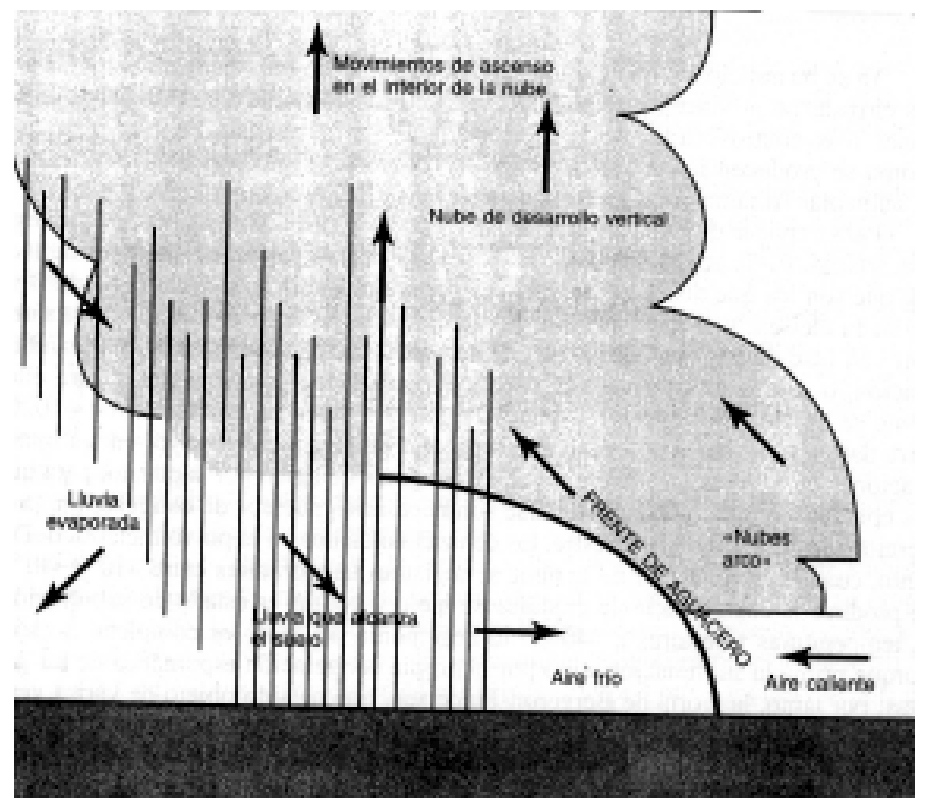

FIGURA 3. Esquema de un «frente de aguacero» generado en una nube de desarrollo vertical. Nótese el paralelismo entre cada una de las partes de éste y la tercera fotografía incluida (vid. Foto 3). Fuente: tomado de Gil y Olcina, 1997: 153.

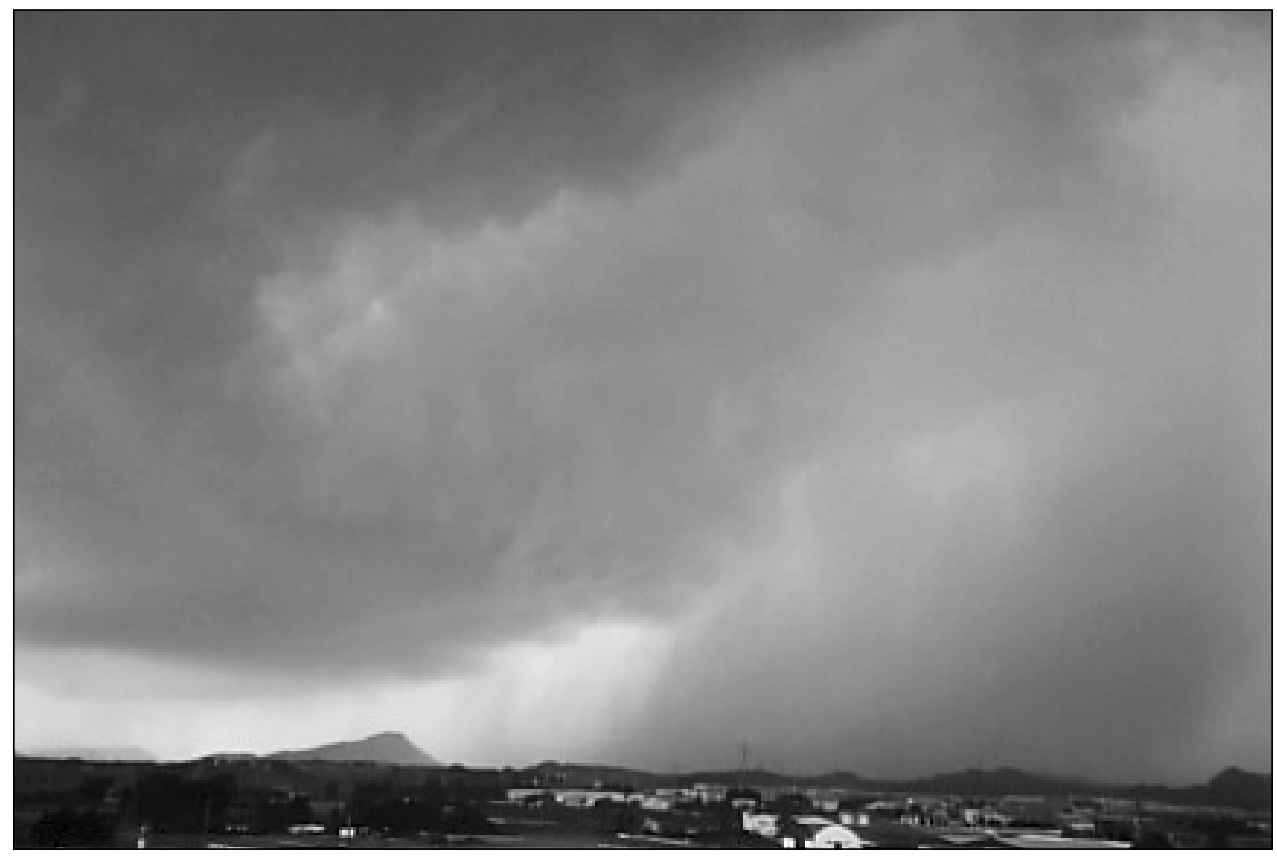

Fото 3. Frente de brisa inestable, frente de aguacero o turbonada en plena actividad sobre la cubeta de Villena. 27 de abril de 2001, 19’35 h. 
sumamente cálido y húmedo, con elevada capacidad de retención de vapor de agua. Asimismo, mientras la célula convectiva se desplazaba desde el borde interior de la cubeta de Villena, la entrada del influjo marino a través de la bocana del Vinalopó animaba los procesos termoconvectivos y la contínua renovación de calor y humedad en el seno de la célula convectiva.

Ilustrativa se presenta, en su caso, la tercera imagen, donde se sintetiza el esquema de todo frente de brisa generado en una nube de desarrollo vertical. Al mismo tiempo, se individualizan y enumeran, a continuación, las partes y elementos más significativos del frente de brisa activo de la tarde del día 27 de abril de 2001. Además de la fotografía incluida, se ha complementado con un gráfico donde se representa el esquema un frente de aguacero o gust front (vid. Figura 3).

- A la derecha (ONO), el aire frío, más denso, se acopla en forma de cuña sobre el cálido.

- A la izquierda de éste (SSE), aire cálido y húmedo (por ende, menos denso), conducido por sirocos procedentes de la línea de fractura transversal del Vinalopó, es proyectado en la vertical (retroalimentación de la célula tormentosa).

- Jirones desgarrados (Cumulonimbus arcus, en forma de rodillo arqueado), conocidos técnicamente con el nombre de pannus, preceden a la línea frontal (frente de aguacero o gust front).

- De la base de la nube tormentosa se desprende una nítida virga o cortina de precipitación, que difumina con un gris uniforme las estribaciones montañosas de la sierra Alhácera. En primer plano, se observa el breve y gallardo cabezo de la Virgen.

El frente de brisa activo, frente de aguacero o turbonada, también se conoce con el nombre de «línea de salto barométrico» (Gil y Olcina, 1997: 152) haciendo alusión a los fuertes contrastes y variaciones de presión de distinto signo que operan tras el paso de este meteoro. Acompañado del salto de presión, los demás elementos meteorológicos experimentan también notables variaciones, detalladas a continuación:

Con el chaparrón que acompaña al paso de la cortina de precipitación se produce un salto o modificación del resto de las variables climáticas (Jansá, 1968: 114-115).

- Como se ha comentado, la presión atmosférica subió de forma brusca y repentina (salto barométrico de 1.013 a $1.016 \mathrm{mb}$ ).

- La temperatura bajó del orden de 5 a $10^{\circ} \mathrm{C}$ en apenas una hora, de $18-19^{\circ} \mathrm{C}$ a las 19 horas, momentos antes de producirse el chubasco, a $10-11^{\circ} \mathrm{C}$ pasado prácticamente éste. Acompañado del descenso térmico, el valor mínimo de la jornada se registraba entrada la noche $\left(8^{\prime} 6^{\circ} \mathrm{C}\right)$.

- La fracción de saturación se elevó de manera continuada, quedando muy cercana a la unidad.

- El viento racheado en el momento de la precipitación, recobraba su componente primitiva, soplando con rachas moderadas de componente sureste-este (sirocolevante) entrada la noche.

Las abundantes descargas eléctricas, pronto reconocibles por los radares meteorológicos más cercanos (radar Doppler instalado en la sierra de la Pila, Murcia) como líneas de débil eco, abandonaron las tierras del término villenense a partir de las 20'30 horas. En estos momentos, la parte marginal del foco convectivo se retiraba lentamente hacia el interior de la cuenca del Mediterráneo Occidental. Junto a este activo foco convectivo, responsable de la lluvia y granizo precipitado sobre las tierras del curso alto del Vinalopó (sur de Valencia y norte de Alicante), un segundo de ellos, de menor intensidad, afectaba a algunas comarcas de Valencia y Castellón. La primera línea de turbonada de la primavera 

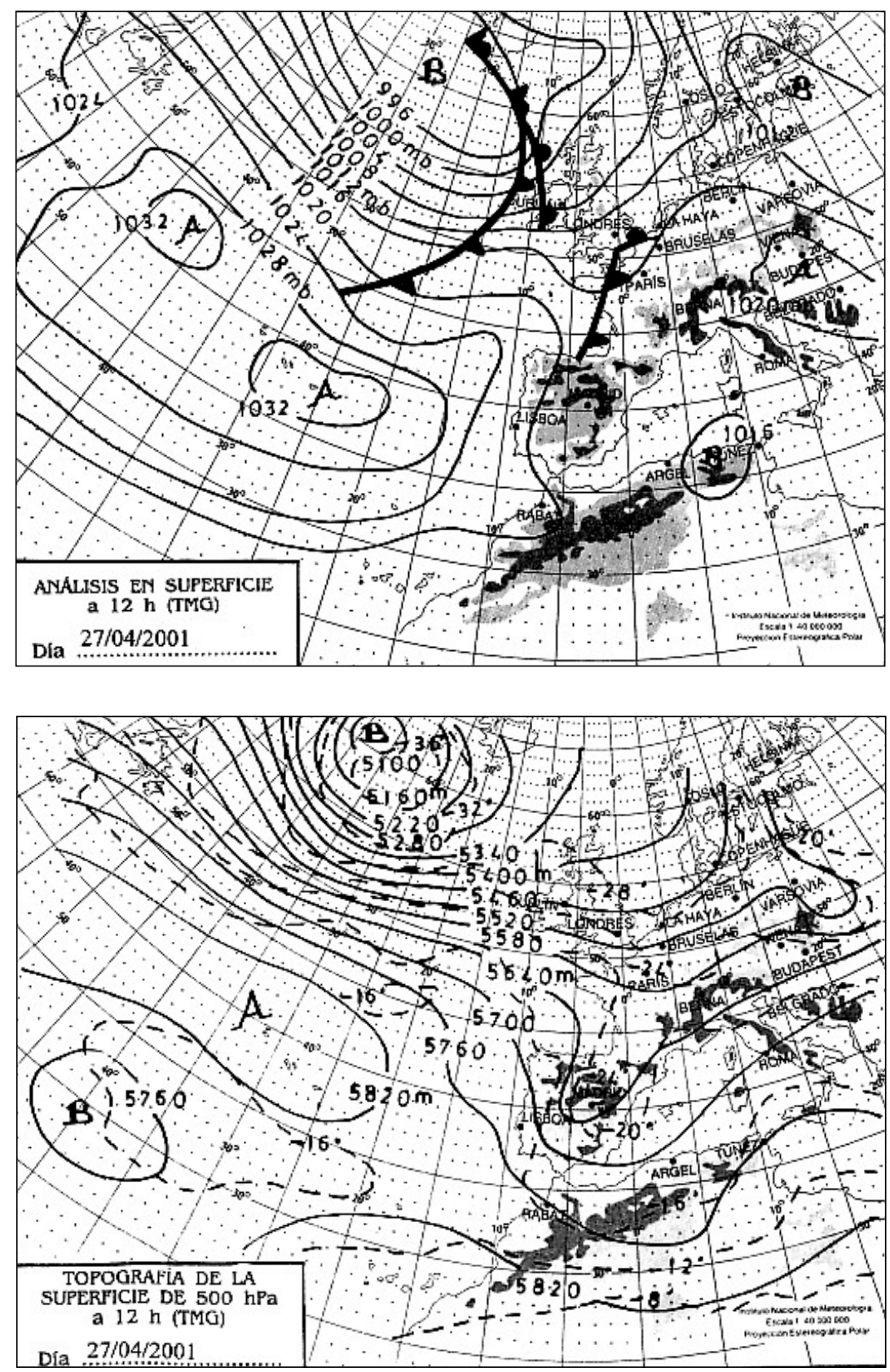

MAPA 1 y 2. A la izquierda, análisis en superficie a las 12 h. (T.M.G.). 27 de abril de 2001. Situación de pantano barométrico o marasmo sobre la cuenca del Mediterráneo Occidental. A la derecha, topografía absoluta de $500 \mathrm{hPa}$, a la misma hora, con onda corta atmosférica de aire Pm centrada sobre la península, con borde de ataque sobre la mitad oriental de España. Fuente: Boletín Meteorológico Diario. Instituto Nacional de Meteorología (INM). 
de 2001 dejaba un total de 17'2 mm de lluvia en el núcleo urbano de Villena que, unidos a los registrados durante la noche, acumularon un total de precipitación de $21^{\prime} 8 \mathrm{~mm}$. Sorprendentemente, durante la mañana del día 28 de abril, parte de los cultivos hortofrutícolas de la cubeta de Villena amanecieron notablemente dañados y afectados por el granizo, acumulado incluso a primeras horas en las parcelas de cultivo de la huerta villenense. Sobre la ciudad de Villena, la lluvia limpia, tan sólo acompañada de hielo granulado de diámetro inferior a 0'5 mm, contrastaba con la fuerte granizada precipitada apenas a 500 ó 1000 metros a las afueras del núcleo urbano. Según datos recopilados, buena parte de la citada huerta, la finca de «el Puntal», «los Frutales» o parajes colindantes $\mathrm{a}$ «la Vereda», padecieron los efectos perniciosos del granizo, mientras las tierras del borde occidental del término villenense (pedanía de «las Virtudes», El Zaricejo, Estrecho Pipa, etc.) quedaron al margen del fuerte aguacero (lluvia completamente inapreciable). De hecho, las fincas afectadas por la granizada no esperaron e inmediatamente comenzaron a efectuar tratamientos con atomizadores dirigidos a facilitar la cicatrización de las heridas en las variedades de fruta (con utilización del producto fungicida tipo «captan» para la

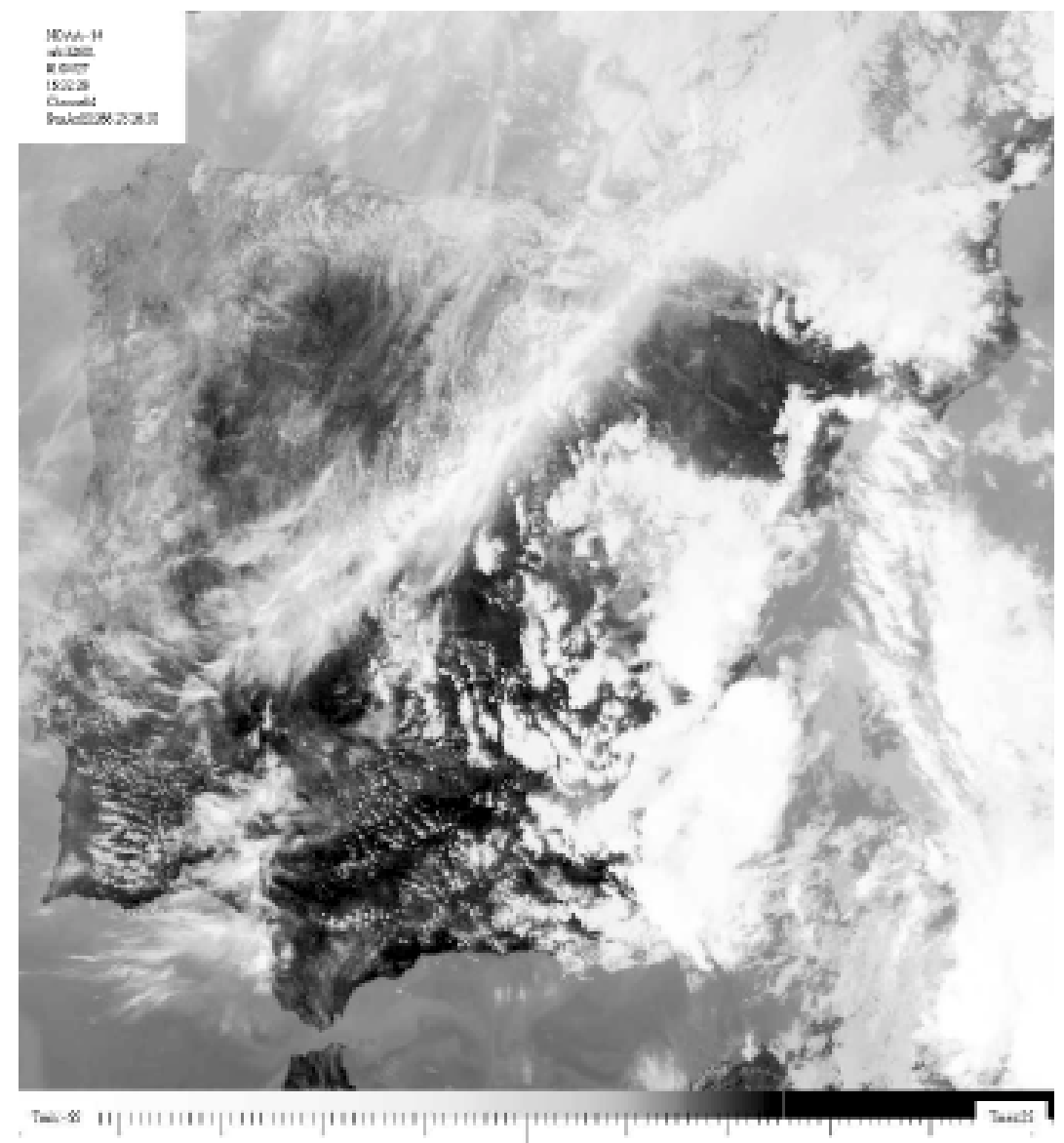

IMAGEN 1. Imagen visible. Activos focos convectivos desarrollados sobre el borde oriental de la península Ibérica. NOAA-14. 27 de abril de 2001. 
cicatrización de heridas producidas por el granizo), puesto que en esta época, dado el reducido tamaño de la fruta, todavía era posible recuperar buena parte de la cosecha del año. Los totales pluviométricos más importantes registrados en distintos observatorios meteorológicos repartidos por la geografía valenciana durante la tarde del día 27 de abril de 2001, fueron los siguientes: Sax $48 \mathrm{~mm}$, Carrícola $47 \mathrm{~mm}$, Bélgida $26 \mathrm{~mm}$, Bañeres 25 $\mathrm{mm}$, Chelva $21 \mathrm{~mm}$, Elda $20 \mathrm{~mm}$, Higueruelas $15 \mathrm{~mm}$ y Villafamés $10 \mathrm{~mm}$. Se acompañan, a continuación, los mapas de tiempo e imágen de satélite, además de los datos climáticos de Villena relativos al singular evento meteorológico analizado; el frente de brisa activo de 27 de abril de 2001.

\begin{tabular}{|c|c|c|c|cc|}
\hline & $\mathbf{T}^{\mathbf{a}}\left({ }^{\mathbf{}} \mathbf{C}\right)$ & $\mathbf{H}^{\mathbf{a}}(\boldsymbol{\%})$ & Pres. $(\mathbf{m b})$ & $\mathbf{P}(\mathbf{m m})$ & Viento \\
\hline Máxima & $25^{\prime} 1$ & 93 & 1.017 & \multirow{2}{*}{$21^{\prime} \mathbf{8} / \mathbf{O} / \Delta / \Omega$} & SE/Variable \\
\cline { 1 - 4 } Mínima & $8^{\prime} 6$ & 20 & 1.012 & & \\
\hline
\end{tabular}

Fuente: Observatorio meteorológico propio. Villena (ciudad).

\section{Conclusiones de trabajo}

La relación de frentes de brisa inestables que han afectado a tierras del interior alicantino durante los últimos lustros se completa, junto a otros de menor rango, con los episodios atmosféricos de precipitación de lluvia intensa y granizo de 7 de junio de 1999 y 31 de agosto de 2001. El primero de ellos estuvo focalizado sobre el corredor orográfico de los Alhorines (pedanía de la Zafra) y Valle de Benejama, a favor de flujos en chorro del tercer cuadrante en altitud. La tromba de agua y granizo, del tamaño éste de una nuez o avellana, duró apenas 20 minutos (entre las 20 y 20'30 horas), suficientes para precipitar alrededor de $50 \mathrm{~mm}$ sobre la citada pedanía de Villena (el observatorio meteorológico oficial de la finca «la Vereda» apenas llegó a medir $6 \mathrm{~mm}$ de precipitación), en una franja estrecha, no superior a los $3 \mathrm{~km}$ de anchura. Pérdidas próximas al $100 \%$ en los cultivos de viñedo, cereales, albaricoqueros, cerezas y ciruelos, inundaciones en sótanos y garajes, numerosos arrastres de tierra y problemas en el corte del fluido eléctrico afectaron a muchas poblaciones del norte de la provincia de Alicante y sur de Valencia: margen septentrional del término villenense, Cañada, Benejama, Bañeres, Fontanares, Fuente la Higuera, Cocentaina y Alcoy ${ }^{11}$. A su vez, fuertes y virulentas fueron las tormentas formadas en puntos del este de Castilla-La Mancha e interior de la vecina Región de Murcia y Alicante durante la tarde del día 31 de agosto de 2001, en un verano caracterizado por el desarrollo de frentes de brisa estables. Este episodio meteorológico nos sirve de ejemplo para matizar una idea que ha sido denunciada reiteradamente por muchos expertos en materia de Climatología; la importancia que debe ser concedida a los estudios de clima local. En este sentido, no recuerdo mal que las predicciones lanzadas por varios modelos de predicción meteorológica de consolidada difusión en los medios de comunicación del país no fueron nada acertadas, puesto que preveían tiempo estable, soleado y de calma atmosférica para toda la jornada del día 31 de agosto en la seca región del sureste ibérico. En cambio, la entrada

11 Vid. Periódico «Información» a fecha 8 de junio de 1999 y «La Verdad» de 9 de junio de 1999. En ambos diarios se recoge la evaluación de pérdidas económicas causadas en el agro de la comarca alicantina del Alto Vinalopó por el pedrisco de la tarde del día 7 de junio de 1999. Según informaron técnicos en agricultura y el Sindicato de Jóvenes Agricultores, los daños sufridos por el pedrisco se elevaron a más de 300 millones, siendo el área afectada por la granizada próxima a las 1.000 ha. 
desde primeras horas de la mañana de una circulación superficial intensa de flujos del segundo cuadrante (en Villena, el viento de componente sureste recibe el nombre de «alicantino», aludiendo a su procedencia marítima) junto a la invasión de aire anormalmente frío sobre la troposfera media y superior, desarrollaron un frente de brisa activo anclado sobre el borde interior de la cubeta de Villena. La célula convectiva, que se desplazó a través del corredor del Valle de Benejama a favor de corrientes en chorro de componente oeste, perdió actividad en su desplazamiento hacia el pasillo de Agres, al tiempo que los observatorios del extremo meridional del término de Villena y comarca del Medio Vinalopó quedaron al margen del copioso e intenso aguacero de lluvia y granizo: «la Vereda» $56 \mathrm{~mm}$, Bañeres $36 \mathrm{~mm}$, Bocairente $4 \mathrm{~mm}$ y Villena (ciudad) 3'6 mm.

$\mathrm{Al}$ amparo de todas estas ideas apuntadas, puede concluirse que los frentes de brisa activos, frentes de aguacero o turbonadas representan, junto a las secuencias secas o de indigencia pluviométrica y los episodios de frío intenso (heladas de advección, tardías o «negras»), un evento meteorológico que engendra de manera más o menos cíclica cuantíosas pérdidas económicas en el agro de esta comarca del interior alicantino. En este sentido, el agricultor ha encontrado en estos episodios atmosféricos, los frentes de brisa inestables con precipitación de núcleos sólidos, un importante factor limitativo, riesgo o amenaza de primer orden para éste, que se ha visto obligado a establer políticas de lucha y defensa antigranizo, con el fin de asegurar sus precarias rentas anuales. El criterio geográfico, basado en la delimitación de áreas de riesgo y afección frecuente de tormentas de granizo, explica la regresión de la superficie en cultivos de frutal durante las últimas décadas de la pasada centuria, a partir de las severas tormentas de granizo de 1974, 1975 y 1979, prolongadas durante los ochenta con el singular episodio atmosférico de 25 y 26 de julio de 1986. A estas granizadas y pedriscos, se debe el retroceso acelerado en cultivos de frutal en el llamado «triángulo del manzano» (declive en las producciones de manzanas de la variedad «starking»), conformado por los municipios de Yecla, Caudete y Villena, así como la reafirmación de una antigua tradición de lucha antigranizo (Olcina et. al., 1996: 20). Entre las actuaciones puestas en marcha en las tierras del tramo alto del Vinalopó con fin de mitigar los efectos derivados del granizo, sobresalen: 1) El servicio de cohetería (lanzamiento de cohetes, siembra de nubes con yoduro de plata) que, desde mediados del pasado siglo, fue auspiciado por la Hermandad Sindical Agraria de Villena, 2) La difusión de mallas antigranizo, técnica ésta algo gravosa económicamente pero de una eficacia inusitada en la lucha contra este hidrometeoro y 3) Contratación de polizas de seguros bajo el impulso de las subvenciones concedidas por las administraciones competentes; nacional y por CC.AA.

Por todo ello, el presente artículo ha tenido por objeto justificar la importancia conjunta de vientos de carácter local y configuración geomorfológica en la génesis y desarrollo de frentes de brisa activos en los valles interiores de la comarca alicantina del Alto Vinalopó, de consecuencias perniciosas para el agro de todas estas tierras.

\section{Agradecimientos}

Quiero expresar mi más sincero agradecimiento a D. Enrique Matarredona Coll, catedrático del Departamento de Análisis Geográfico Regional de la Universidad de Alicante, por el interés depositado en la publicación de este estudio. Gratitud que hago extensiva a D. Jorge Olcina Cantos, profesor titular de Análisis Geográfico Regional y responsable del Laboratorio de Climatología en la Universidad de Alicante, por sus inestimables consejos y sugerencias. 


\section{Bibliografía}

BARRY, R.G. y CHORLEY, R.J. (1998): Atmósfera, tiempo y clima, Ed. Omega, Barcelona, 395 pp. GARCÍA FERNÁNDEZ, J.(1986): El Clima de Castilla y León, Ed. Ámbito, Valladolid, 370 pp.

GIL OLCINA, A. (dir.) (2000): Cartografía temática de las tierras alicantinas, Instituto Universitario de Geografía, Universidad de Alicante, Alicante, pp. 32-33.

GIL OLCINA, A. y OLCINA CANTOS, J.(1997): Climatología general, Ed. Ariel Geografía, Barcelona, $579 \mathrm{pp}$.

GIL OLCINA, A. y OLCINA CANTOS, J.(1998): Diccionario de Climatología, Ed. Acento, Madrid, 93 pp.

JANSÁ GUARDIOLA, J.Mª (1968): Manual del observador de Meteorología, I.N.M., Madrid, $2^{\text {a }}$ edición, $432 \mathrm{pp}$.

MARTÍN VIDE, J. (1991): Mapas de tiempo: fundamentos, interpretación e imágenes de satélite, Ed. Oikos-Tau, Barcelona, $2^{\mathrm{a}}$ edición, $170 \mathrm{pp}$.

OLCINA CANTOS, J. (1994): Riesgos Climáticos en la Península Ibérica, Ed. Penthalon, Madrid, $440 \mathrm{pp}$.

OLCINA CANTOS, J. (1994): Tormentas y granizadas en las tierras alicantinas, Universidad de Alicante-IUG, Alicante, $317 \mathrm{pp}$.

OLCINA CANTOS, J. (1995): Episodios meteorológicos de consecuencias catastróficas en tierras alicantinas, Instituto de Cultura Juan Gil-Albert, San Vicente/Alicante, 376 pp.

OLCINA CANTOS J., RICO AMORÓS, A.M. y SUCH CLIMENT, Ma P. (1993): «Incidencia de episodios meteorológicos catastróficos en la actividad agraria del valle del Vinalopó (Alicante)», en Papeles de Geografía, no 19, Departamento de Geografía, Universidad de Murcia, Murcia, pp. 53-67.

OLCINA CANTOS, J., RICO AMORÓS, A.M. y JIMÉNEZ RODRÍGUEZ, A. (1996): «Las tormentas de granizo en la Comunidad Valenciana: cartografía de riesgo en la actividad agraria», en Investigaciones Geográficas, $\mathrm{n}^{\circ}$ 19, Instituto Universitario de Geografía, Universidad de Alicante, Alicante, pp. 5-29.

OLCINA CANTOS, J. y MIRÓ PÉREZ, J. (1998): «Influencia de las circulaciones estivales de brisa en el desarrollo de tormentas convectivas», en Papeles de Geografía, n 28, Departamento de Geografía, Universidad de Murcia, Murcia, pp. 109-132.

OMM. (1993): Atlas Internacional de Nubes. Manual de observación de nubes y otros meteoros, Secretaría de la Organización Meteorológica Mundial (O.M.M.), Ginebra, 159 pp.

PÉREZ CUEVA, ALEJANDRO J. (Coord.) (1994): Atlas climático de la Comunidad Valenciana (1961-1990), Conselleria d'Obres Públiques Urbanisme i Transports, Valencia, 208 pp.

SOLER GARCÍA, J.M ${ }^{a}$. (1993): Diccionario Villenero, Instituto de Cultura «Juan Gil-Albert» y Fundación José $\mathrm{M}^{\mathrm{a}}$ Soler, Villena, 326 pp. 